\section{JURNAL EKONOMI EFEKTIF}

ISSN : $2622-8882$, E-ISSN : 2622-9935

Jurnal Ekonomi Efektif, Vol. 4, No. 2, Januari 2022

@ Prodi Manajemen Fakultas Ekonomi

Universitas Pamulang

\title{
PENGARUH DISIPLIN TERHADAP KINERJA KARYAWAN PADA PT GLENINDO CITRA ABADI DI JAKARTA
}

\author{
Muhammad Firman ${ }^{*}$, Heri Ginanjar ${ }^{2}$, Derry Nugraha ${ }^{3}$ \\ STKIP PGRI Sukabumi, Jawa Barat, Indonesia \\ muhammadfirman@stkippgrisukabumi.ac.id", heriginanjar@stkippgrisukabumi.ac.id, \\ derrynugraha@stkippgrisukabumi.ac.id
}

Manuskrip: Oktober -2021; Ditinjau: November: -2021; Diterima: November-2021; Online: Januari -2022; Diterbitkan: Januari-2022

\begin{abstract}
ABSTRAK
Penelitian ini bertujuan untuk mengetahui pengaruh disiplin terhadap kinerja karyawan pada PT. Glenindo Citra Abadi di Jakarta. Metode yang digunakan adalah explanatory research dengan sampel sebanyak 97 responden. Teknik analisis menggunakan analisis statistik dengan pengujian regresi, korelasi, determinasi dan uji hipotesis. Hasil penelitian ini variabel disiplin diperoleh nilai rata-rata skor sebesar 3,418 dengan kriteria baik. Variabel kinerja karyawan diperoleh nilai rata-rata skor sebesar 3,845 dengan kriteria baik. Disiplin berpengaruh positif dan signifikan terhadap kinerja karyawan dengan nilai persamaan regresi $\mathrm{Y}=9,393+0,850 \mathrm{X}$, dan nilai koefisien korelasi 0,766 atau memiliki tingkat hubungan yang kuat dengan nilai determinasi 58,7\%. Uji hipotesis diperoleh signifikansi $0,000<0,05$.
\end{abstract}

\section{Kata Kunci: Disiplin, Kinerja Karyawan}

\begin{abstract}
This study aims to determine the effect of discipline on employee performance at PT. Glenindo Citra Abadi in Jakarta. The method used is explanatory research with a sample of 97 respondents. The analysis technique uses statistical analysis with regression testing, correlation, determination and hypothesis testing. The results of this study, the discipline variable obtained an average score of 3,418 with good criteria. Employee performance variables obtained an average score of 3.845 with good criteria. Discipline has a positive and significant effect on employee performance with a regression equation value of $Y=9.393+$ $0.850 X$, and a correlation coefficient value of 0.766 or has a strong level of relationship with a determination value of $58.7 \%$. Hypothesis testing obtained a significance of $0.000<0.05$.
\end{abstract}

Keywords: Discipline, Employee Performance 


\section{PENDAHULUAN}

\section{A. Latar Belakang Masalah}

Dalam rangka membangun suatu perusahaan yang survive, maka maka tuntutan kesadaran akan pentingnya kualitas Sumber Daya Manusia (SDM) yang merupakan salah satu respon dalam menyikapi perubahan tersebut sangatlah penting. Sumber Daya Manusia (SDM) yang berkualitas sangat penting artinya bagi suatu perusahaan. Bahkan ketersediaan SDM berkualitas diyakini sebagai kunci utama keberhasilan. Oleh karena itu, untuk mewujudkan SDM yang berkualitas, perlunya peran serta yang optimal dari pihak perusahaan sendiri sebagai wadahpengembangan bagi SDM itu sendiri (investasi SDM)

Karena sumber Daya Manusia (SDM) merupakan sumber daya paling vital yang menjadi penentu keberhasilan suatu perusahaan, oleh sebab itu perlu diberikan hak-hak yang dapat memacu meningkatkan kinerjannya, ada beberapa faktor yang dapat mendorong karyawan meningkatkan kinerjanya antara salah satunya adalah pemberian disiplin yang dilakukan pemimpin di perusahaan kepada karyawan.

Sumber daya manusia sebagai unsur utama pada suatu lembaga memiliki peranan yang sangat besar dalam upaya mencapai tujuan yang telah ditetapkan. Peran sumber daya manusia ini kemudian berkembang mengikuti perkembangan organisasi, ilmu pengetahuan dan teknologi. Sumber daya manusia memegang peranan yang sangat menentukan karena bagaimanapun hebat dan canggihnya teknologi yang digunakan tanpa didukung oleh manusia sebagai pelayan operasionalnya, tidak akan mampu menghasilkan suatu output yang sesuai dengan tingkat efisiensi yang tinggi. Oleh karna itu pengembangan sumber daya manusia dalam suatu organisasi menjadi sangat penting, semua itu dimulai dari disiplin.

Disiplin yang baik mencerminkan besarnya rasa tanggung jawab seseorang terhadap tugas-tugasnya yang diberikan kepadanya. Hal ini mendorong gairah kerja, dan terwujudnya tujuan perusahaan, karyawan, dan masyarakat. Oleh karena itu, setiap manajer selalu berusaha agar pada bawahannya mempunyai disiplin yang baik. Seorang manajer dikatakan efektif dalam kepemimpinannya, jika karyawannya berdisiplin baik. Untuk memelihara dan meningkatkan kedisiplinan yang baik adalah hal yang sulit. Karna banyak faktor yang mempengaruhinya.

Peraturan sangat diperlukan untuk memberikan bimbingan dan penyuluhan bagi karyawan PT. Glenindo Citra Abadi dalam menciptakan tata tertib yang baik, semangat kerja, moral kerja, efisiensi, dan efektivitas kerja karyawan akan meningkat. Jika karyawan PT. Glenindo Citra Abadi tidak mematuhi peraturan-peraturan perusahaan tersebut, akan sulit mencapai tujuannya perusahaan. Kedisiplinan suatu perusahaan dikata baik, jika sebagian besar karyawan mentaati peraturan-peraturan yang ada.

Kedisiplinan adalah fungsi operatif keenam (yaitu: perencanaan, pengorganisasian, pengarahan, pengawasan, pengendalian, pengadaan) dari manajer sumber daya manusia. Kedisiplinan merupakan fungsi manajemen sumber daya manusia yang terpenting, karena semakin baik disiplin karyawan, semakin tinggi prestasi kerja yang dapat di capainya. Tanpa disiplin karyawan yang baik, sulit bagi organisasi mencapai hasil yang optimal.

Lemahnya respon karyawan di PT. Glenindo Citra Abadi terhadap disiplin kerja dapat dilihat dari karyawan yang masih saja tidak mentaati peraturan perusahaan, ketegasan dalam mengambil sikap juga masih dinilai lemah dari segi karyawan yang masih kurang paham dengan adanya disiplin bekerja.

Untuk mendapatkan sumber daya manusia yang diharapkan oleh organisasi agar memberikan andil positif terhadap semua kegiatan perusahaan dalam mencapai tujuannya, setiap karyawan diharapkan memiliki disiplin kerja yang tinggi sehingga nantinya akan meningkatkan kinerja yang tinggi. Disiplin menurut Kreitner dan Kinicki dalam Wibowo 
(2016), "Disiplin merupakan proses psikologis yang membangkitkan dan mengarahkan prilaku pada pencapaian tujuan atau goal-directed behavior". Manajer perlu memahami proses psikologis ini apabila mereka ingin berhasil membina pekerja menuju pada penyelesaian sasaran organisasi.

Mengingat pentingnya disiplin bagi setiap karyawan, maka perusahaan perlu terus menjaga agar disiplin karyawan tidak menurun. Satu hal yang perlu dipahami setiap karyawan bekerja karena ingin memenuhi kebutuhannya, baik kebutuhan yang disadari maupun kebutuhan yang tidak disadari. Dengan memenuhi kebutuhan-kebutuhan tersebut tentu akan medisiplin karyawan dalam bekerja akan meningkat dan berdampak pada kinerja yang baik dan membantu perusahaan mencapai tujuannya.

Menurut Hasibuan (2017), "Kinerja adalah suatu hasil kerja yang dicapai seseorang dalam melaksanakan tugas-tugas yang dibebankan kepadanya yang didasarkan kepada kecakapan, pengalaman, kesungguhan waktu". Kinerja adalah poin penting dalam kemajuan perusahaan, semakin meningkatnya kinerja karyawan maka akan semakin penting dalam kemajuan perusahaan, semakin meningkatnya kinerja karyawan maka akan semakin cepat tercapainya tujuan perusahaan. Dengan meningkatnya kinerja karyawan maka perusahaan akan memperoleh keuntungan, oleh sebab itu perusahaan perlu terus menjaga agar kinerja karyawan dapat meingkat dari waktu ke waktu. Suatu kerja individu dapat ditingkatkan apabila ada kesesuaian antara pekerjaan dan kemampuannya. Salah satu program manajemen sumber daya manusia adalah menempatkan karyawan pada tempatnya, atau sesuai kemampuan kerjaannya. Program ini ditetapkan untuk mengatasi karyawan yang lambat, tidak semangat, dan tidak teliti.

Jika karyawan yang dipekerjakan tidak memiliki kinerja yang baik yang dibutuhkan perusahaan, maka perusahaan tidak akan mencapai target yang sudah ditetapkan, dan merugikan perusahaan itu sendiri. Oleh sebab itu, dalam penarikan, seleksi, penempatan karyawan harus berdasarkan azas the right man in the right place, and the right man in the right job, yang artinya karyawan perlu ditempatkan pada pekerjaan yang sesuai dengan kemampuannya sangatlah penting untuk mencapai tujuan perusahaan dan kinerja karyawan yang lebih optimal.

Berdasarkan uraian di atas, maka penulis tertarik untuk mengadakan penelitian dengan judul "Pengaruh Disiplin Terhadap Kinerja Karyawan Pada Kantor PT. Glenindo Citra Abadi di Jakarta".

\section{B. Rumusan Masalah}

1. Bagaimana disiplin pada PT. Glenindo Citra Abadi di Jakarta ?.

2. Bagaimana kinerja karyawan pada PT. Glenindo Citra Abadi di Jakarta ?.

3. Adakah pengaruh antara disiplin terhadap kinerja karyawan pada PT. Glenindo Citra Abadi di Jakarta?.

\section{Tujuan Penelitian}

1. Untuk mengetahui kondisi disiplin pada PT. Glenindo Citra Abadi di Jakarta.

2. Untuk mengetahui kondisi kinerja karyawan pada PT. Glenindo Citra Abadi di Jakarta.

3. Untuk mengetahui pengaruh antara disiplin terhadap kinerja karyawan pada PT. Glenindo Citra Abadi di Jakarta.

\section{TINJAUAN PUSTAKA}

\section{Disiplin}

Menurut Sutrisno (2016) mendefinisikan "Disiplin adalah perilaku seseorang yang 
sesuai dengan peraturan, prosedur kerja yang ada atau sikap dan tingkah laku serta perbuatan yang sesuai dengan peraturan dari organisasi baik tertulis maupun tidak tertulis". Dalam penelitian ini indikator yang digunakan meliputi: taat terhadap aturan waktu taat terhadap aturan organisasi, taat terhadap aturan perilaku dalam pekerjaan, taat terhadap peraturan lainnya.

\section{Kinerja Karyawan}

Kinerja karyawan menurut Mangkunegara (2015:9) adalah hasil kerja secara kulalitas dan kuantitas yang dicapai oleh seorang karyawan dalam melaksanakan tugasnya.

\section{METODE PENELITIAN}

\section{Populasi}

Populasi dalam penelitian ini berjumlah 97 responden PT. Glenindo Citra Abadi di Jakarta

2. Sampel

Teknik pengambilan sampling dalam penelitian ini adalah sampel jenuh, dimana semua anggota populasi dijadikan sebagai sampel. Dengan demikian sampel dalam penelitian ini sampel yang digunakan berjumlah 97 responden.

\section{Jenis Penelitian}

Jenis penelitian yang dipakai adalah asosiatif, dimana tujuannya adalah untuk mengetahui atau mencari keterhubungan antara variabel independen terhadap variabel dependennya

\section{Metode Analisis Data}

Dalam menganalisis data digunakan uji validitas, uji reliabilitas, analisis regresi linier sederhana, analisis koefisien korelasi, analisis koefisien determinasi dan pengujian hipotesis.

\section{HASIL PENELITIAN}

\section{Analisis Deskriptif}

Pada pengujian ini digunakan untuk mengetahui skor minimum dan maksimum skor tertinggi, ratting score dan standar deviasi dari masing-masing variabel. Adapun hasilnya sebagai berikut:

\section{Tabel 1. Hasil Analisis Descriptive Statistics}

Descriptive Statistics

\begin{tabular}{lr|r|r|r|r} 
& N & Minimum & Maximum & Mean & Std. Deviation \\
\hline Disiplin (X) & 97 & 28 & 44 & 34.18 & 3.857 \\
\hline Kinerja Karyawan (Y) & 97 & 29 & 49 & 38.45 & 4.282 \\
\hline Valid N (listwise) & 97 & & & & \\
\hline
\end{tabular}

Disiplin diperoleh varians minimum sebesar 28 dan varians maximum 44 dengan ratting score sebesar 3,418 dengan standar deviasi 3,857. Skor ini termasuk pada rentang sakala 3,40-4,19 dengan kriteria baik atau setuju. Kinerja karyawan diperoleh varians minimum sebesar 29 dan varians maximum 49 dengan ratting score sebesar 3,845 dengan standar deviasi 4,282. Skor ini termasuk pada rentang sakala 3,40-4,19 dengan kriteria baik atau setuju.

\section{Analisis Kuantitatif}

Pada analisis ini dimaksudkan untuk mengetahui pengaruh variabel independen terhadap variabel dependen. Adapun hasil pengujian sebagai berikut: 


\section{a. Analisis Regresi Linier Sederhana}

Uji regresi ini dimaksudkan untuk mengetahui perubahan variabel dependen jika variabel independen mengalami perubahan. Adapun hasil pengujiannya sebagai berikut:

Tabel 2. Hasil Pengujian Regresi Linier Sederhana

\begin{tabular}{lr|r|r|r|r}
\multicolumn{1}{c}{$\begin{array}{c}\text { Coefficients } \\
\text { Unstandardized } \\
\text { Coefficients }\end{array}$} & $\begin{array}{c}\text { Standardized } \\
\text { Coefficients }\end{array}$ & & \\
Model & $\mathrm{B}$ & Std. Error & Beta & $\mathrm{t}$ & \multicolumn{1}{c}{ Sig. } \\
\hline 1 (Constant) & 9.393 & 2.518 & & 3.730 & .000 \\
\hline Disiplin $(\mathrm{X})$ & .850 & .073 & .766 & 11.612 & .000 \\
\hline
\end{tabular}

Berdasarkan hasil pengujian pada tabel di atas, diperoleh persamaan regresi $Y$ $=9,393+0,850 X$. Dari persamaan tersebut dijelaskan sebagai berikut:

1) Konstanta sebesar 9,393 diartikan jika disiplin tidak ada, maka telah terdapat nilai kinerja karyawan sebesar 9,393 point.

2) Koefisien regresi disiplin sebesar 0,850 , angka ini positif artinya setiap ada peningkatan disiplin sebesar 0,850 point maka kinerja karyawan juga akan mengalami peningkatan sebesar 0,850 point.

\section{b. Analisis Koefisien Korelasi}

Analisis koefisien korelasi dimaksudkan untuk mengetahui tingkat kekuatan hubungan dari variabel independen terhadap variabel dependen. Adapun hasil pengujian sebagai berikut:

Tabel 3. Hasil Pengujian Koefisien Korelasi Disiplin Terhadap Kinerja Karyawan. Correlations $^{\text {b }}$

\begin{tabular}{llr|r} 
& & & \multicolumn{2}{|c}{ Kinerja Karyawan } \\
& & Disiplin (X1) & \multicolumn{1}{c}{$(\mathrm{Y})$} \\
\hline Disiplin (X) & Pearson Correlation & 1 & $.766^{* *}$ \\
\cline { 2 - 4 } & Sig. (2-tailed) & & .000 \\
\hline Kinerja Karyawan (Y) & Pearson Correlation & $.766^{* *}$ & 1 \\
\cline { 2 - 4 } & Sig. (2-tailed) & .000 & \\
\hline
\end{tabular}

Berdasarkan hasil pengujian diperoleh nilai korelasi sebesar 0,766 artinya disiplin memiliki hubungan yang kuat terhadap kinerja karyawan.

\section{c. Analisis Koefisien Determinasi}

Analisis koefisien determinasi dimaksudkan untuk mengetahui besarnya persentase pengaruh dari variabel independen terhadap variabel dependen. Adapun hasil pengujian sebagai berikut:

Tabel 4. Hasil Pengujian Koefisien Determinasi Disiplin Terhadap Kinerja Karyawan.

Model Summary

\begin{tabular}{|c|c|c|c|c|}
\hline \multicolumn{5}{|c|}{ Model Summary } \\
\hline Model & $\mathrm{R}$ & R Square & $\begin{array}{l}\text { Adjusted R } \\
\text { Square }\end{array}$ & $\begin{array}{l}\text { Std. Error of the } \\
\text { Estimate }\end{array}$ \\
\hline 1 & $.766^{\mathrm{a}}$ & .587 & .582 & 2.767 \\
\hline
\end{tabular}

Berdasarkan hasil pengujian diperoleh nilai determinasi sebesar 0,587 artinya disiplin memiliki kontribusi pengaruh sebesar 58,7\% terhadap kinerja karyawan, sedangkan sisanya sebesar $41,3 \%$ dipengaruhi oleh faktor lain yang tidak dilakukan penelitian. 


\section{d. Uji Hipotesis}

Pengujian hipotesis dengan uji t digunakan untuk mengetahui hipotesis mana yang diterima. Rumusan hipotesis: Terdapat pengaruh yang signifikan antara disiplin terhadap kinerja karyawan.

Tabel 5. Hasil Uji Hipotesis Disiplin Terhadap Kinerja Karyawan.

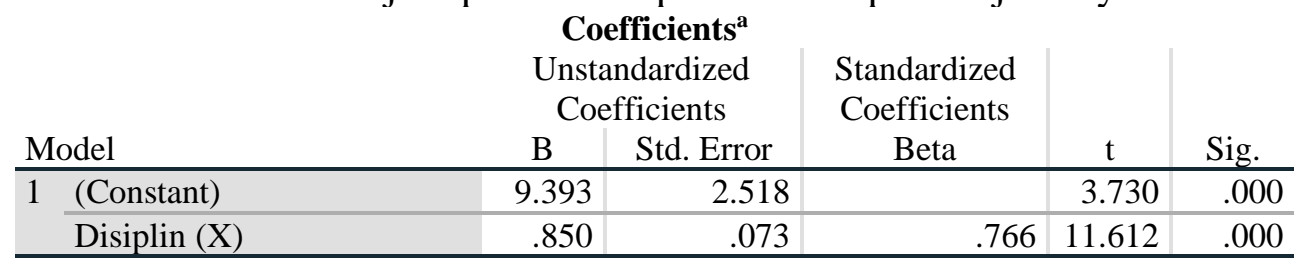

Berdasarkan hasil pengujian pada tabel di atas, diperoleh nilai t hitung $>\mathrm{t}$ tabel atau $(11,612>1,985)$, dengan demikian hipotesis yang diajukan bahwa terdapat pengaruh yang signifikan atara disiplin terhadap kinerja karyawan diterima.

\section{Pembahasan Hasil Penelitian}

\section{Kondisi Jawaban Responden Variabel Disiplin}

Berdasarkan jawaban responden, variabel disiplin diperoleh ratting score sebesar 3,418 berada di rentang skala 3,40 - 4,19 dengan kriteria baik atau setuju.

\section{Kondisi Jawaban Responden Variabel Kinerja Karyawan}

Berdasarkan jawaban responden, variabel kinerja karyawan diperoleh ratting score sebesar 3,845 berada di rentang skala 3,40 - 4,19 dengan kriteria baik atau setuju.

\section{Pengaruh Disiplin Terhadap Kinerja Karyawan}

Disiplin berpengaruh signifikan terhadap kinerja karyawan dengan persamaan regresi $\mathrm{Y}=9,393+0,850 \mathrm{X}$, nilai korelasi sebesar 0,766 atau memiliki hubungan yang kuat dengan kontribusi pengaruh sebesar 58,7\%. Pengujian hipotesis diperoleh nilai t hitung $>\mathrm{t}$ tabel atau $(11,612>1,985)$. Dengan demikian hipotesis yang diajukan bahwa terdapat berpengaruh signifikan antara disiplin terhadap kinerja karyawan diterima.

\section{KESIMPULAN DAN SARAN}

\section{Kesimpulan}

a. Variabel disiplin diperoleh ratting score sebesar 3,418 berada di rentang skala 3,40 4,19 dengan kriteria baik atau setuju.

b. Variabel kinerja karyawan diperoleh ratting score sebesar 3,845 berada di rentang skala 3,40 - 4,19 dengan kriteria baik atau setuju.

c. Disiplin berpengaruh signifikan terhadap kinerja karyawan dengan persamaan regresi $\mathrm{Y}=9,393+0,850 \mathrm{X}$, nilai korelasi sebesar 0,766 atau kuat dan kontribusi pengaruh sebesar 58,7\% sedangkan sisanya sebesar 41,3\% dipengaruhi faktor lain. Uji hipotesis diperoleh nilai $t$ hitung $>\mathrm{t}$ tabel atau $(11,612>1,985)$.

\section{Saran}

a. Perusahaan harus menegakkan peraturan dengan baik sesuai dengan ketentuan yang berlaku guna menjamin karyawan diperlakukan dengan adil.

b. Perusahaan harus selalu memberikan semangat dan apresiasi yang layak untuk memastikan karyawan memiliki semangat kerja yang tinggi.

c. Kinerja perusahaan dapat ditingkatkan dengan memberdayakan karyawan dengan menegakkan peraturan yang baik dan pemberian motivasi yang lebih inten lagi. 


\section{DAFTAR PUSTAKA}

Algifari. (2015). "Analisis Regresi untuk Bisnis dan Ekonomi”. Yogyakarta: BPFE.

Amir, Mohammad Faisal, "Manajemen Kinerja Perguruan Tinggi", Mitra Wacana Media, Jakarta, 2016.

Arikunto, Suharsimi, "Prosedur Penelitian Suatu Pendekatan Praktek", PT. Rineka Cipta, Jakarta, 2015.

Bangun, Wilson. 2012. "Manajemen Sumber Daya Manusia”. Jakarta: Erlangga

Barsah, A. (2019). Pengaruh Motivasi Dan Disiplin Terhadap Kinerja Pegawai Pada Dinas Kependudukan Dan Pencatatan Sipil Kota Tangerang. JENIUS (Jurnal Ilmiah Manajemen Sumber Daya Manusia), 3(1), 1-15.

Bejo Siswanto (2013) Manajemen Tenaga Kerja Rancangan dalam Pendayagunaan dan Pengembangan Unsur Tenaga Kerja”, Bandung: Sinar Baru.

Bungin, Burhan, "Metodologi Penelitian Sosial dan Ekonomi", Prenada Media Group, Jakarta, 2013.

Edi Sutrisno (2016). Manajemen Sumber Daya Manusia. Jakarta: Prenadamedia Group.

Gerry Dessler (2016) Human Resources Management, Prenticehall, London: International Inc.

Handoko (2016) Manajemen Personalia dan Sumberdaya Manusia. Yogyakarta: BPFE.

Hasibuan, Malayu S.P. (2016). Manajemen Sumber Daya Manusia. Edisi Revisi. Jakarta: PT Bumi Aksara.

Imam Ghozali (2017). "Aplikasi Analisis Multivariate Dengan Program SPSS”. Edisi Kelima. Semarang: Badan Penerbit Undip.

Istijianto, “Aplikasi Praktis Riset Pemasaran”, Gramedia Pustaka Utama, Jakarta, 2012.

Jasmani, J., \& Paeno, P. (2019). The Effect of Leadership and Competence on Lecturer Performance and Its Implications on Student Learning Motivation at Pamulang University. International Journal of Advances in Social and Economics, 1(4).

Jasmani, J., \& Sunarsi, D. (2020). The Influence of Product Mix, Promotion Mix and Brand Image on Consumer Purchasing Decisions of Sari Roti Products in South Tangerang. PINISI Discretion Review, 1(1), 165-174.

Luthans Fred (2014) Organizational Behavior, Ney York: McGraw-Hill, New York.

Mangkunegara, Prabu Anwar. (2016). Evaluasi Kinerja SDM. Cetakan ke tujuh, PT Refika Aditama: Bandung.

Nurjaya, N., Sobarna, A., Affandi, A., Erlangga, H., \& Sarwani, S. (2020). Edupreneurship management in shaping the nation's character. Jurnal Konseling dan Pendidikan, 8(3), 198-206.

Sareno, S. (2019). Pengaruh Kedisiplinan Terhadap Prestasi Kerja Karyawan Pada PT. Handaru Nusantara Gemilang (Dapoer Intan). JENIUS (Jurnal Ilmiah Manajemen Sumber Daya Manusia), 2(2), 244-259.

Sedarmayanti (2016) Manajemen Sumber Daya Manusia, Reformasi Birokrasi dan Manajemen Karyawan Negeri Sipil, Cetakan Kelima, Bandung: PT Refika Aditama.

Sudjana (2014) “Metode Statistika”, Bandung: Tarsido.

Sugiyono (2017), "Metode Penelitian Administrasi : dilengkapi dengan Metode $R$ \& D”. Bandung: Alfabeta.

Suharsimi Arikunto "Prosedur Penelitian Suatu Pendekatan Praktek", PT. Rineka Cipta, Jakarta, 2013.

Suntoyo, Danang, "Penelitian Sumber Daya Manusia”. PT Buku Seru, Jagakarsa, 2015.

Veithzal Rivai (2015) Manajemen Sumber Daya Manusia Untuk Perusahaan, Jakarta: Raja Grafindo Persada.

Wibowo (2015) Manajemen Kinerja, Jakarta: PT. Raja Grafindo Persada. 